\title{
STUDY ON THE USE OF PALM KERNEL SHELL AND PERIWINKLE SHELL AS COARSE AGGREGATES IN CONCRETE
}

\author{
Sulaiman A.O \\ Department of Civil and Environmental Engineering, \\ Faculty of Engineering, University of Lagos, Akoka
}

\begin{abstract}
This study investigates the performance of palm kernel shells (PKS) and periwinkle shells (PS) as coarse aggregates in concrete. A total of 80 cubes and 80 cylinders were produced in a laboratory. Forty cubes and 40 cylinders were produced with replacement materials for granite (i.e. Palm Kernel Shells and Periwinkle Shells). The replacement was done from $0 \%$ to $100 \%$ in steps of $25 \%$ (i.e. $0 \%, 25 \%$, $50 \%, 75 \%, 100 \%)$. The strength of the concrete cubes and cylinders were measured in 7, 14, 21 and 28 -days, using single batch mix of 1:2:4 (i.e. cement, sand, coarse aggregate) and 0.6 water/cement ratio. Slump test (workability), compressive strength test and split cylinder test were conducted. The results showed that, compressive and tensile strengths decrease as PKS and PS content increases, which allow specific area to increase, thus requiring more cement paste to bond effectively with the shells. The result also revealed that for all curing ages, palm kernel shell concrete (PKSC) have lower compressive strength and tensile strength than periwinkle shell concrete (PSC). The compressive strength and tensile strength of the 28-day PKSC with $100 \%$ replacement were $4.33 \mathrm{~N} / \mathrm{mm}^{2}, 3.68 \mathrm{~N} / \mathrm{mm}^{2}$, respectively; that of PSC at $100 \%$ replacement were $5.89 \mathrm{~N} / \mathrm{mm}^{2}, 4.95 \mathrm{~N} / \mathrm{mm}^{2}$, respectively; and granite concrete without any replacement were $25.11 \mathrm{~N} / \mathrm{mm}^{2}, 11.74 \mathrm{~N} / \mathrm{mm}^{2}$, respectively. It is concluded that both PKSC and PSC satisfied the compressive strength and tensile strength requirement of light weight concrete, although PS has better gradation and bonding to cement than PKS. This implies that PS is best suited as replacement for granite in concrete than PKS. It is recommended that the mix-ratio should be altered to get higher values of compressive strength.
\end{abstract}

Keywords: palm kernel shell, periwinkle shell, lightweight concrete.

\section{INTRODUCTION}

Concrete is the most popular material used in construction work, its main component is a mixture of cement, fine aggregate, coarse aggregate and water. According to Falade, Ikponmwosa and Ojediran (2010), the volume of concrete is composed of about $70 \%-80 \%$ of coarse aggregate, which means the percentage of coarse aggregate is of considerable importance. Structural

\author{
Olatunde O.A. \\ Department of Building, Faculty of Environmental \\ Sciences, University of Lagos, Akoka
}

lightweight materials can be defined as a type of concrete, which include an expanding agent (i.e. lightweight aggregate) that increase the volume of mixture while giving additional qualities and reduce the dead weight. Although the engineering properties of shells are generally satisfactory, there is little effort made in comparing palm kernel shell concrete with other different types of lightweight concrete. The reason is palm kernel shell is incapable of producing concrete with a compressive strength above $30 \mathrm{MPa}$ (Okafor, 1988). This study evaluates the properties of lightweight concretes using palm kernel shells and periwinkle shells as partial replacements for granite in concrete.

Efforts by researchers have been spent on the possible use of the shells as coarse aggregate but little or no effort has been made in the construction industry on the possibility of using the shell as coarse aggregate either wholly or partially in structural concrete. The rise in the need for concrete in the construction industry using natural weight aggregate such as granite or gravel reduced the availability of natural stones and has damage the environment leading to imbalance of ecological system (Short and Kinniburg, 1978). The choice of locally available materials depends on four main factors, such as strength, economy, compatibility, and availability. This study seeks to compare the suitability of palm kernel shells and periwinkle shells as coarse aggregate in lightweight concrete. Palm kernel shell was partially a waste in the 1990 s and early 2000 , more than 350,000 tons were available for sale, especially in concrete work (Mohammed, 2007).

The aim of this study is to compare the performance of palm kernel shell concrete and periwinkle shell concrete when its partially replaced in crushed rock aggregate concrete with a view to determine the suitability of PKS and PS as aggregate for concrete production while its objective is to determine the mechanical performance of PKS and PS at various percentage of granite replacements.

\section{METHODOLOGY}

\subsection{MATERIALS FOR THE STUDY}

The River sand used would be obtained through a local supplier from Ogun River bed located at Ogun state. The particles size range used are those passing through BS sieve $11 \mathrm{~mm}$ but retained on BS sieve $0.075 \mathrm{~mm}$ ensuring that the dust particles were 


\section{International Journal of Engineering Applied Sciences and Technology, 2019 \\ Vol. 4, Issue 3, ISSN No. 2455-2143, Pages 454-460 \\ Published Online July 2019 in IJEAST (http://www.ijeast.com)}

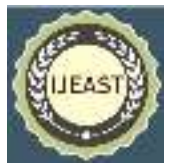

removed from the sand. The coarse aggregate to be used in this research study are crushed granite of igneous origin. They come in different sizes, but the recommended size is $12.5 \mathrm{~mm}$ to $19 \mathrm{~mm}$. It helps to improve the strength of the concrete. Water used was be portable, clean and free from impurities and organic matter of any type.

The cement to be used is Ordinary Portland cement (Dangote Portland Cement). This cement satisfies international standards on cement (BS 12 Portland Cement). The Palm Kernel Shells to be used were gotten from Anambra State in the South Eastern Part of Nigeria while the Periwinkle Shells were gotten from Lagos State in the South Western Part of Nigeria.

\subsection{SAMPLES AND SELECTION}

A sample size is a representation of whole population. The sample size according to Saunders et al. (2009) reflects the proportion of a given target population that are examined by the researcher towards answering of research questions and crafting relevant conclusions and recommendations. In a study where a survey (quantitative) research design has been chosen, determination of the sample size is considered important (Saunders et al, 2009). For the purpose of this study a total of eighty (80) cubes and eighty (80) cylinders would be cast in all. Forty (40) cubes and forty (40) cylinders would be cast for each replacement material (Palm Kernel Shells and Periwinkle Shell). The replacement was done from $0 \%$ t0 $100 \%$ in steps of $25 \%$ $(0 \%, 25 \%, 50 \%, 75 \%, 100 \%)$. Two cubes out of the eight cubes cast for each percentage replacement would be used to determine the 7,14, 21 and 28-day strength of the cubes. This also applies for the cylinders.

\subsection{EXPERIMENTAL PROCEDURES}

The experimental procedure began with the preliminary investigation on the basic materials to be used to determine their physio - mechanical properties. The various investigations include the following: Sieve Analysis (Particle Size Distribution), Specific gravity, Moisture content, Aggregate crushing value, Bulk \& Dry densities. The secondary investigations carried out in the course of this research study include the following: Slump test (workability) and Compressive strength test.

\subsection{COMPOSITION OF CONCRETE MIX}

A single batch mix 1:2:4 (i.e. cement: sand: coarse aggregate) would be used during mixing of the concrete cubes for a 0.6 water/cement ratio. The prescribed mix proportion would be used i.e. the mixes were specified by weight and are given in BS 8110 (Structural Use of Concrete). The batches would be mixed in a tray. The surface of the tray wetted before mixing to avoid water absorption and to ensure the same mixing conditions for all mixes. Two samples would be used for each test and the average of two results would be adopted. The tests would be conducted in the concrete laboratory of the University of Lagos, Akoka.

\section{FINDINGS AND DISCUSSIONS}

\subsection{WORKABILITY}

Workability is the measure of the amount of useful internal works necessary to be done on a concrete mix to produce full compaction. A standard measure of workability of wet concrete mix is the slump. The workability of the fresh concrete was determined by the slump test in accordance with section 7.2 of BS 5328. Table 1 presents the slump values for all the mix proportions with different percentages of granite replaced with periwinkle shells and palm kernel shells.

\begin{tabular}{ccc}
\hline $\begin{array}{c}\text { Percentage } \\
\text { Replacement } \\
\begin{array}{c}\text { Granite- } \\
\text { Replacement } \\
\text { Material }\end{array}\end{array}$ & $\begin{array}{c}\text { PKS } \\
\text { Slump } \\
\text { Value } \\
(\mathrm{mm})\end{array}$ & $\begin{array}{c}\text { PS } \\
\text { Slump } \\
\text { Value }(\mathrm{mm})\end{array}$ \\
\hline $0-100$ & 43 & 43 \\
$25-75$ & 33 & 40 \\
$50-50$ & 28 & 35 \\
$75-25$ & 24 & 28 \\
$100-0$ & 17 & 21 \\
\hline
\end{tabular}

Table 1: Slump Values and Degree of Workability

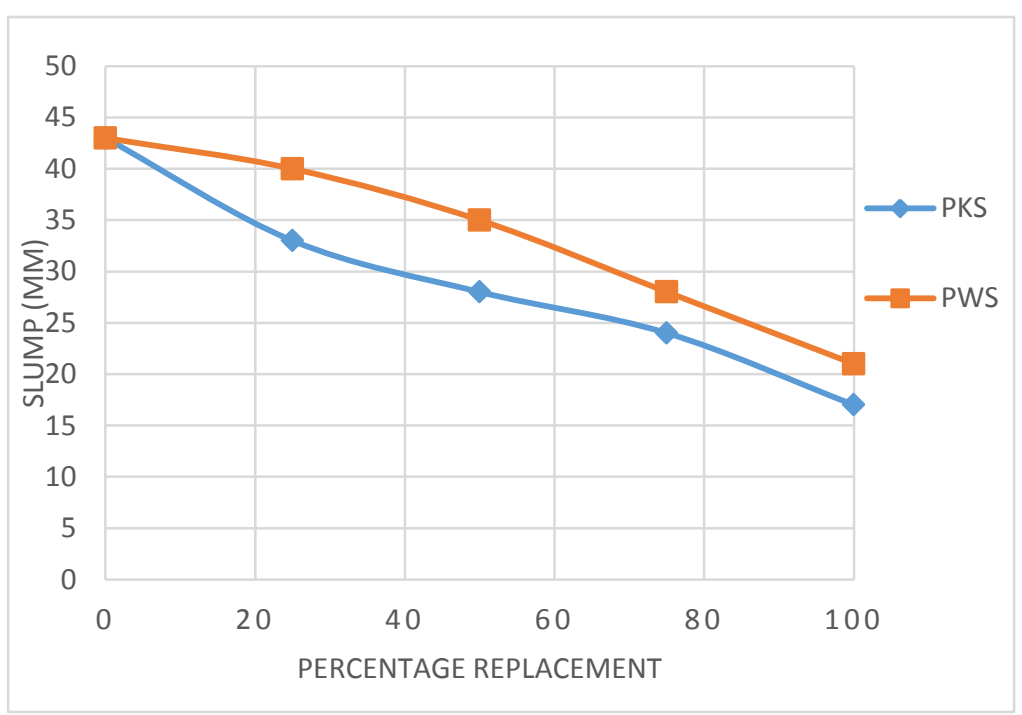

Fig 1: Variation of Workability with Percentage Material 


\section{International Journal of Engineering Applied Sciences and Technology, 2019 \\ Vol. 4, Issue 3, ISSN No. 2455-2143, Pages 454-460 \\ Published Online July 2019 in IJEAST (http://www.ijeast.com)}

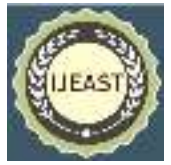

From Figure 1, it can be observed that the workability decreased from $43 \mathrm{~mm}$ to $17 \mathrm{~mm}$ as the content of replacement increased from $0 \%$ to $100 \%$ replacement of granite with PKS; and from 43 $\mathrm{mm}$ to $21 \mathrm{~mm}$ at $0 \%$ to $100 \%$ replacement of granite with PS.

The increase in workability gives an indication that the water absorption property of PKS and PS is high compared to granite, which causes improper bonding in the interfacial transition zone. Hence more water is required to make the mix more workable (Echeta et al., 2013).

\subsection{COMPRESSIVE STRENGTHS OF CONCRETE}

Compressive strength was found out at the ages 7, 14, 21 and 28 days after moist curing the specimens. Strength of concrete mainly depends on three factors viz. Strength of coarse aggregate; Strength of mortar matrix; Bond strength between mortar part and coarse aggregate;

Two cubes each were cast for each percentage ranging from $0 \%$ to $100 \%$ in steps of $25 \%$, which was subjected to up to 28 days of curing. The test results are presented in tables 2 and 3.

\subsubsection{PALM KERNEL SHELL}

It is seen that the compressive strength decreases as palm kernel shells content increases. The compressive strength is maximum at $0 \%$ replacement by PKS and minimum at $100 \%$ replacement. As palm kernel shell content increases, the specific area increases, thus requiring more cement paste to bond effectively with the shells. Since the cement content remains the same, the bonding is therefore inadequate. Strength depends to a large extent on good bonding between the cement paste and the aggregates. The compressive strength reduces because of the increase in percentage replacement of granite.

\section{DAYS}

\begin{tabular}{ccccc}
\hline $\begin{array}{c}\text { Granite- } \\
\text { PKS }\end{array}$ & 7 & 14 & 21 & 28 \\
\hline $0-100$ & 17 & 19.22 & 20.89 & 25.11 \\
$25-75$ & 11.11 & 14.67 & 16.11 & 16.56 \\
$50-50$ & 8.56 & 9.67 & 9.78 & 12.22 \\
$75-25$ & 3.67 & 3.89 & 4.56 & 5.56 \\
$100-0$ & 3.11 & 3.33 & 3.89 & 4.33
\end{tabular}

Table 2: Compressive Strength Values (PKS)

From Table 2, it is observed that at 28-day curing age, the control, having $0 \%$ PKS inclusion specimens decreased by $34.05 \%$ when compared with $25 \%$ replacement of granite with PKS and by $51.33 \%$ when compared with $50 \%$ replacement of granite with PKS. These values are $77.86 \%$ and $82.76 \%$ for the $75 \%$ and $100 \%$ replacements respectively.

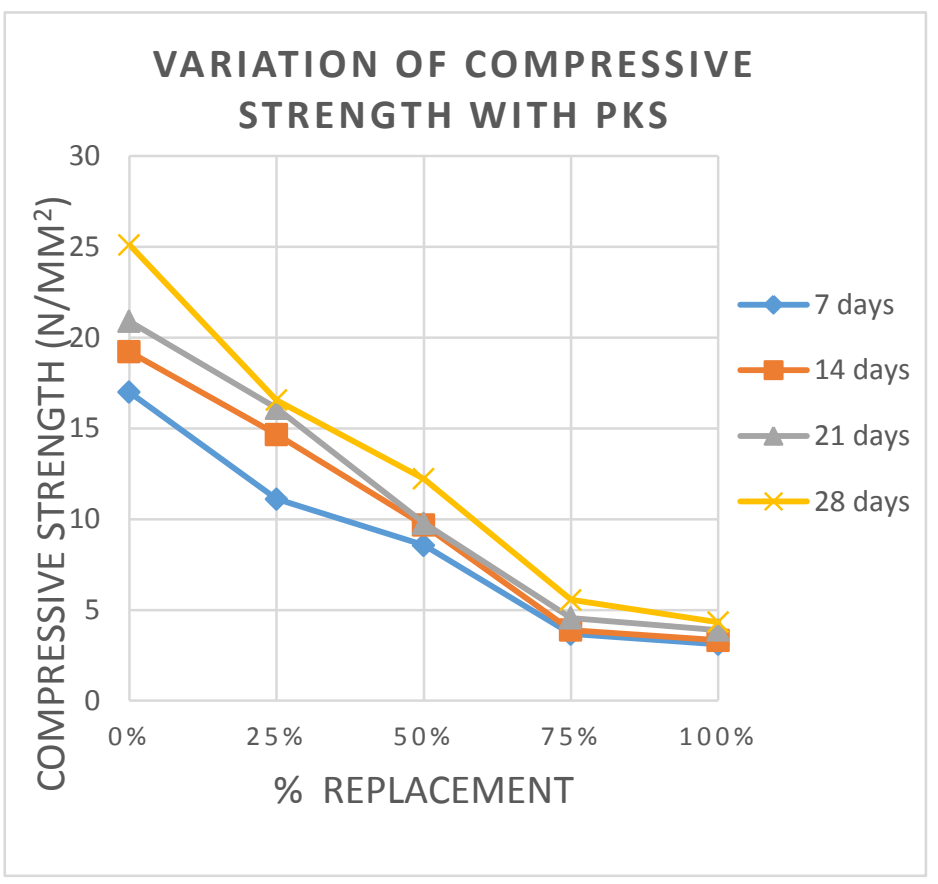

Fig 2: Variation of Compressive Strength with PKS

From Figure 2, the general trend shows a linear relationship between the percentage replacement and the compressive strength and there is general reduction in the compressive strength values when compared to the control. The strength value decreases as the percentage replacement increases from control to $100 \%$ replacement. This is an indication that, the substitution of granite with PKS beyond the $25 \%$ replacement level is not recommended for use in heavy loaded structure. It was also observed that for every percentage replacement, there is an increasing trend in the compressive strength due to the effect of the curing age.

It was also observed that the average value of $15 \mathrm{~N} / \mathrm{mm}^{2}$ may be used for Non-Critical Structural Works as stated in CIP-(Concrete in Practice), as well as the American Society for Testing \& Materials (ASTM C31/39), however, values higher than $15 \mathrm{~N} / \mathrm{mm}^{2}$ are very suitable for Critical Structural Works, but values lower than this benchmark would be suitable for NonCritical and Non-Structural Works. As shown in Table 3 and in Figure 2, 25\% replacement of granite with PKS can be used for non-critical structural works.

Apart from the compressive strengths observed, partial replacement of granite with PKS in concrete production gives significant reduced weight and densities as compared with normal concrete. Use of PKS in concrete production is thus advantageous 


\section{International Journal of Engineering Applied Sciences and Technology, 2019 \\ Vol. 4, Issue 3, ISSN No. 2455-2143, Pages 454-460 \\ Published Online July 2019 in IJEAST (http://www.ijeast.com)}

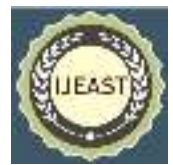

in concrete production as the dead loads (self-weight) of concrete elements are substantially reduced in a structure.

\subsubsection{PERIWINKLE SHELL}

It is seen that the compressive strength decreases the as periwinkle shells content increases. The compressive strength is maximum at $0 \%$ replacement by PS and minimum at $100 \%$ replacement. As periwinkle shell content increases, the specific area increases, thus requiring more cement paste to bond effectively with the shells. Since the cement content remains the same, the bonding is therefore inadequate. Strength depends to a large extent on good bonding between the cement paste and the aggregates. The compressive strength reduces as a consequence of the increase in percentage replacement of granite.

\section{DAYS}

\begin{tabular}{ccccc} 
Granite- PS & 7 & 14 & 21 & 28 \\
& & & & \\
\hline $0-100$ & 17 & 19.22 & 20.89 & 25.11 \\
$25-75$ & 14.45 & 14.22 & 16.22 & 20.67 \\
$50-50$ & 12.89 & 13.56 & 13.67 & 15.11 \\
$75-25$ & 5 & 5.22 & 7.34 & 8.89 \\
$100-0$ & 3.67 & 3.56 & 4.56 & 5.89 \\
\hline
\end{tabular}

Table 3: Compressive Strength Values (PS)

From Table 3, it is observed that at 28-day curing age, the control, having $0 \%$ PS inclusion specimens decreased by $17.68 \%$ when compared with $25 \%$ replacement of granite with PS and by $39.82 \%$ when compared with $50 \%$ replacement of granite with PS. These values are $64.6 \%$ and $76.54 \%$ for the $75 \%$ and $100 \%$ replacements respectively.

From Figure 3, the general trend shows a linear relationship between the percentage replacement and the compressive strength and there is general reduction in the compressive strength values when compared to the control. The strength value decreases as the percentage replacement increases from control to $100 \%$ replacement. This is an indication that, the substitution of granite with PS beyond the 50\% replacement level is not recommended for use in heavy loaded structure. It was also observed that for every percentage replacement, there is an increasing trend in the compressive strength due to the effect of the curing age.

It was also observed that the average value of $15 \mathrm{~N} / \mathrm{mm}^{2}$ may be used for Non-Critical Structural Works as stated in CIP-(Concrete in Practice), as well as the American Society for Testing \& Materials (ASTM C31/39), however, values higher than $15 \mathrm{~N} / \mathrm{mm}^{2}$ are very suitable for critical structural works, but values lower than this benchmark would be suitable for Non-Critical and

\section{VARIATION OF COMPRESSIVE STRENGTH WITH PS}

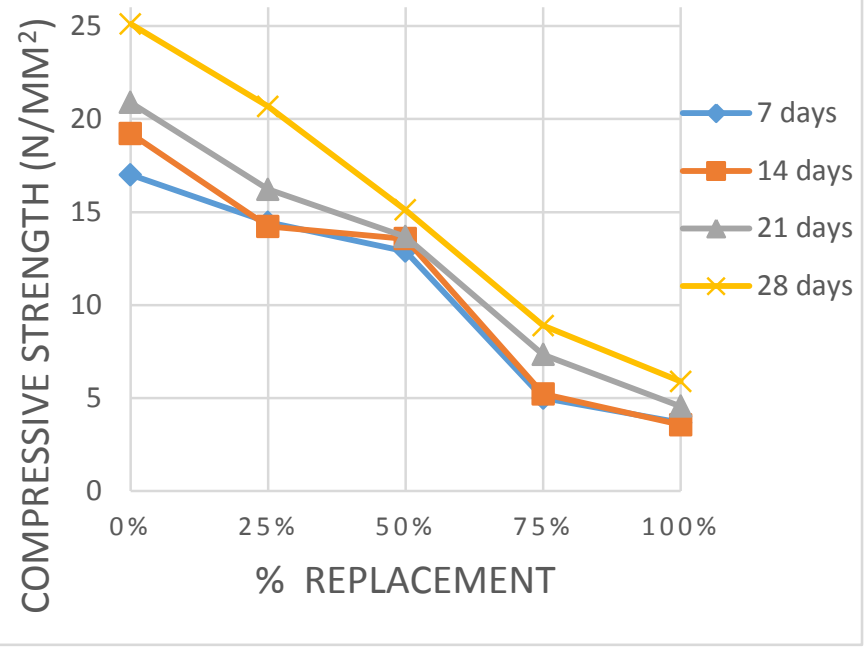

Fig 3: Variation of Compressive Strength with PS

Non-Structural Works. As shown in Tables 4 and in Figure 3, $25 \%$ and $50 \%$ replacement of granite with PS can be used for non-critical structural works.

Apart from the compressive strengths observed, partial replacement of granite with PS in concrete production gives significant reduced weight and densities as compared with normal concrete. Use of PS in concrete production is thus advantageous in concrete production as the dead loads (self-weight) of concrete elements are substantially reduced in a structure.

\subsection{TENSILE STRENGTH OF CONCRETE CYLINDERS}

The splitting tensile strength is generally greater than direct tensile strength and lower than flexural strength (modulus of rupture). Splitting tensile strength is used to find the tensile strength of concrete. Two cylinders each were cast for each percentage ranging from $0 \%$ to $100 \%$ in steps of $25 \%$ Replacement which subjected from 7 days to 28 days of curing in steps of 7 days. The test results are presented in tables 4 and 5 .

\subsubsection{PALM KERNEL SHELL}

From Figure 4, It was also observed that for each percentage replacement, there is variation in the tensile strength. At 28 days, the tensile strength for the conventional concrete was found to be $11.74 \mathrm{~N} / \mathrm{mm}^{2}$ while that of $25 \%$ replacement of granite with PKS was $8.35 \mathrm{~N} / \mathrm{mm}^{2}$ and $50 \%$ replacement was $7.08 \mathrm{~N} / \mathrm{mm}^{2}$. These values are $5.8 \mathrm{~N} / \mathrm{mm}^{2}$ and $3.68 \mathrm{~N} / \mathrm{mm}^{2}$ for the $75 \%$ and $100 \%$ replacements respectively. It was observed that tensile strength 


\section{International Journal of Engineering Applied Sciences and Technology, 2019 Vol. 4, Issue 3, ISSN No. 2455-2143, Pages 454-460 \\ Published Online July 2019 in IJEAST (http://www.ijeast.com)}

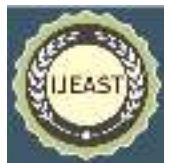

decreased as percentage replacement increased and the tensile strength at the control was found to be higher than other replacement.

As curing age increases from 0 to 28 days, a gradual increase in tensile strength was observed. The general trend shows a linear relationship between the curing ages and the tensile strength and it was uniform for all percentage replacement along its curing ages.

\section{DAYS}

\begin{tabular}{ccccc} 
Granite- PKS & 7 & 14 & 21 & 28 \\
\hline $0-100$ & 6.23 & 9.2 & 10.89 & 11.74 \\
$25-75$ & 4.25 & 6.37 & 7.36 & 8.35 \\
$50-50$ & 3.68 & 5.66 & 6.65 & 7.08 \\
$75-25$ & 3.11 & 3.54 & 3.68 & 5.8 \\
$100-0$ & 2.12 & 2.41 & 2.83 & 3.68
\end{tabular}

Table 4: Tensile Strength Values (PKS)

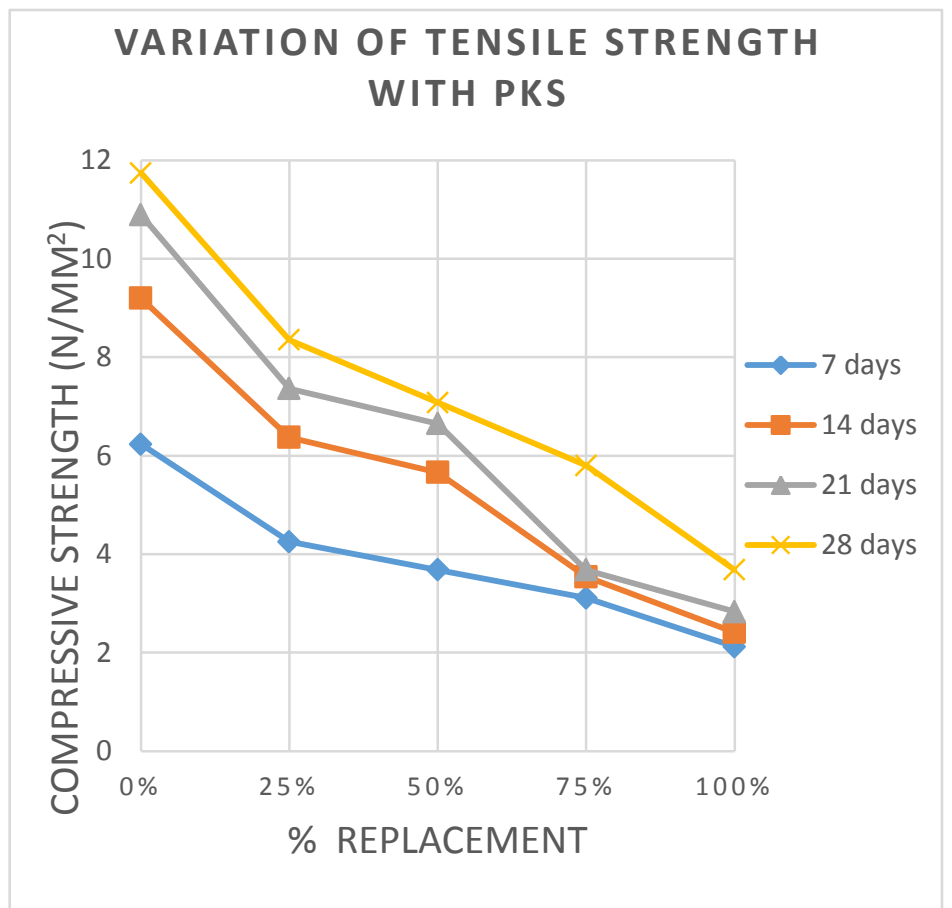

Fig 4: Variation of Tensile Strength with PKS
Tensile strength is not usually considered in reinforced co ncrete design (except in water retaining structures) because concrete is poor in tensile strength. It is however of considerable importance in resisting cracking due to changes in moisture content or temperature.

\subsubsection{PERIWINKLE SHELL}

From Figure 5, It was also observed that for each percentage replacement, there is variation in the tensile strength. At 28 days, the tensile strength for the conventional concrete was found to be $11.74 \mathrm{~N} / \mathrm{mm}^{2}$ while that of $25 \%$ replacement of granite with PS was $10.33 \mathrm{~N} / \mathrm{mm}^{2}$ and $50 \%$ replacement was $8.35 \mathrm{~N} / \mathrm{mm}^{2}$. These values are $7.22 \mathrm{~N} / \mathrm{mm}^{2}$ and $4.95 \mathrm{~N} / \mathrm{mm}^{2}$ for the $75 \%$ and $100 \%$ replacements respectively. It was observed that tensile strength decreased as percentage replacement increased and the tensile strength at the control was found to be higher than other replacement.

As curing age increases from 0 to 28 days, a gradual increase in tensile strength was observed. The general trend shows a linear relationship between the curing ages and the tensile strength and it was uniform for all percentage replacement along its curing ages. Tensile strength is not usually taken into account in reinforced concrete design (except in water retaining structures) because concrete is poor in tensile strength. It is however of considerable importance in resisting cracking due to changes in moisture content or temperature.

\begin{tabular}{ccccc}
\hline & \multicolumn{5}{c}{ DAYS } \\
\hline Granite- PS & 7 & 14 & 21 & 28 \\
\hline $0-100$ & 6.23 & 9.2 & 10.89 & 11.74 \\
$25-75$ & 5.66 & 8.63 & 9.05 & 10.33 \\
$50-50$ & 5.38 & 7.22 & 8.63 & 8.35 \\
$75-25$ & 4.81 & 5.1 & 5.52 & 7.22 \\
$100-0$ & 3.54 & 4.39 & 4.39 & 4.95 \\
\hline
\end{tabular}

Table 5: Tensile Strength Values (PS)

From this research work, based on required compressive strength, periwinkle shells could be used as partial replacement of granite in making concrete for reinforced concrete works. This confirms some of the observations of Ettu et al (2013) They concluded that 


\section{International Journal of Engineering Applied Sciences and Technology, 2019 Vol. 4, Issue 3, ISSN No. 2455-2143, Pages 454-460 \\ Published Online July 2019 in IJEAST (http://www.ijeast.com)}

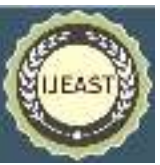

the use of periwinkle shells for this purpose would greatly reduce the cost of concrete works in riverine communities with plentiful supply of these shells. They also concluded that as much as $75 \%$ replacement could still produce concrete of satisfactory strength for structural members under mild conditions of exposure, given good supervision of the concrete making process which conforms with the findings from this research work with $75 \%$ replacement of granite with periwinkle shells given strength value of 8.89 $\mathrm{N} / \mathrm{mm}^{2}$ at 28 days.

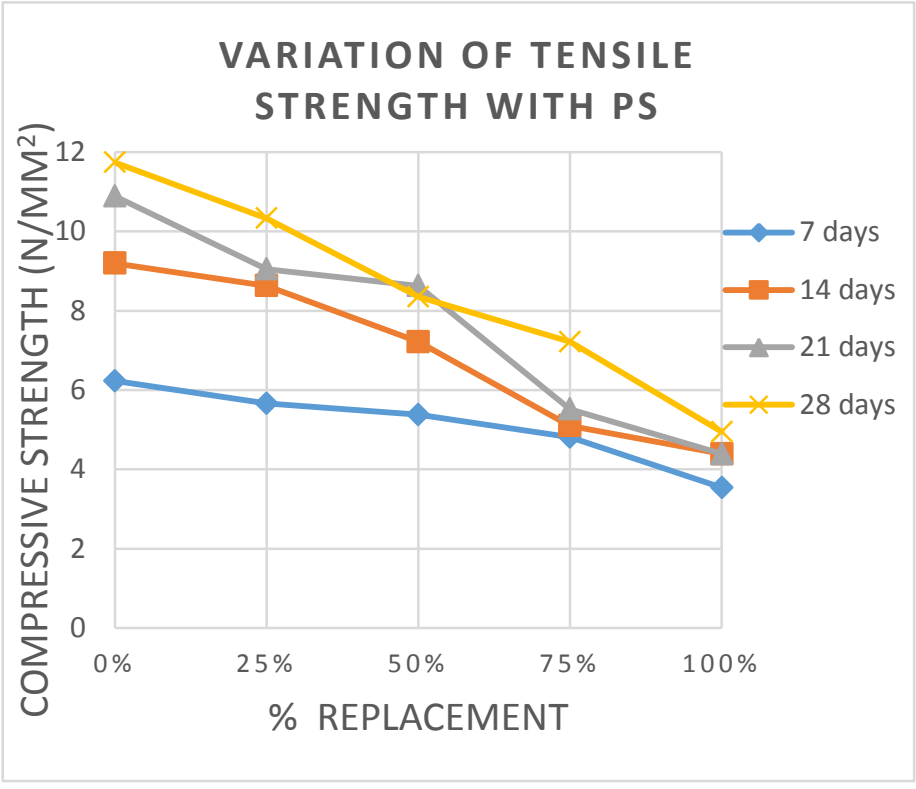

Fig 5: Variation of Tensile Strength with PS

Lower percentage replacements would be suitable for worse conditions of exposure. For example, 50 percent replacement would be satisfactory for moderate conditions of exposure that require a minimum concrete compressive strength of $30 \mathrm{~N} / \mathrm{mm}^{2}$; and $25 \%$ and lower percentage replacements could be suitable for severe conditions that require strengths of $35 \mathrm{~N} / \mathrm{mm}^{2}$ or more. The reduced density of concrete produced when granitic chippings are partially replaced with periwinkle shells also results in lower selfweight of structure. This is particularly beneficial in coastal communities where the soils have relatively low bearing capacities.

\section{CONCLUSION}

1. The characteristic strength of $25.11 \mathrm{~N} / \mathrm{mm}^{2}$ of the $0 \%$ replacement is the highest.

2. Palm Kernel Shells and Periwinkle shells was found to have a lesser ability to resist crushing which is a fundamental reason why there is a decline in the compressive strength value.

3. The $25 \%$ and $50 \%$ replacement of granite with PS can be used for non-critical structural works while only the 25\% replacement of granite with PKS can be used for noncritical structural works.

4. The values of compressive and tensile strengths were found to be higher for PS than they were for PKS for each percentage replacement.

5. PKS and PS can be successfully used only as partial replacement and never as total replacement of granite in concrete production for both structural and nonstructural applications.

6. For every percentage, the compressive strength of the concrete increases from a minimum at a curing age of 7 days to a maximum at 28 days.

7. Finally, the environmental drivers must not be overlooked as PKS and PS incorporation into concrete on an appropriate selective basis would provide solution to problems encountered in waste management. When used as aggregates to substitute granite, this constitutes a positive response to global environmental problems such as high carbon dioxide emissions generated by Portland cement production. In addition, it would reduce extraction of natural materials such as limestone.

\section{REFERENCES}

1. Ameh, O. J., Afuye, I. T., \& Amusan, L.M. (2014). Prospect of Lateritic Sand and Periwinkle Shell as Aggregates in Concrete. Asian Journal of Engineering, Sciences \& Technology, 49(2),53-64.

2. Echeta, C. B., Ikponmwosa, E. E., \& Fadipe. A. O. (2013). Effect of Partial Replacement of Granite with Washed Gravel on the Characteristic Strength and Workability of Concrete. ARPN Journal of Engineering and Applied Sciences. 8(11), 498-505.

3. Falade, F., Ikponmwosa, E. E., \& Ojediran, N. I. (2010). Behavior of lightweight concrete containing periwinkle shell at elevated temperature. Journal of Engineering Science and Technology, 5(4),379-390. 
4. Mohammed, D. (2007). Palm Kernel Shell (PKS) is More than Biomass for Alternative Fuel after 2005: Proceedings of Chemistry and Technology Conference, Malaysia.

5. Okafor, F.O. (1988). Palm kernel shell as a lightweight aggregate for concrete. Cement and Concrete Research Journal. 18(6), 901-910.

6. Osei, D.Y., \& Jackson, E.N. (2012). Experimental Study on Palm Kernel Shells as Coarse Aggregate in Concrete. International Journal of Scientific and Engineering Research, 3(8), 1-6.

7. Short, A., \& Kinniburgh, W. (1978). Lightweight Concrete, 3 editions: London: Applied Science.

8. Williams, F.N., Ijigah, E.A., Anum, I., Isa, R.B., \& Obanibi, A.O. (2014). Suitability of Palm Kernel Shell as Coarse Aggregate in Lightweight Concrete Production. International Journal of Civil and Engineering Research, 6(7), 55-59. 